\title{
Operational Aspects of Vertical Navigation during the Approach Phase of Flight: CDA vs. Conventional Step-Down Approach
}

\author{
Petar ANDRAŠI*, Doris NOVAK, Antonio RATKOVIĆ
}

\begin{abstract}
The continuous descent approach (CDA) is an operational technique used by aircraft when descending from cruise altitude; the aim is to minimize thrust and thereby avoid horizontal flight segments. CDA involves vertical navigation calculations that modify flight trajectory according to altitude; these procedures can reduce fue consumption, emission of toxic exhaust gases, and noise due to the aircraft and its engines. In order to verify some of these benefits under field conditions in Croatia, the present study analysed fuel consumption, approach distance and approach duration during 44 landings by Croatia Airlines Dash-8 Q400 aircraft at the airport in Split, Croatia. CDA was performed at $426 \mathrm{~km} / \mathrm{h}$ (230 knots) or at high speed, and these procedures were compared with the standard step-down approach involving a flight speed of 426 $\mathrm{km} / \mathrm{h}$ (230 knots) and an18.5 km-long (10 NM) horizontal segment at an altitude of $914 \mathrm{~m}(3000 \mathrm{ft})$. The different approach conditions were compared in terms of fuel consumption. The results indicate that implementing CDA can provide small fuel savings on individual flights, and that these savings can be significant when calculated over an entire fleet on an annual basis. The significant reduction in fuel consumption should also mean a reduction in $\mathrm{CO}_{2}$ emissions.
\end{abstract}

Keywords: Continuous descent approach (CDA); fuel management; vertical navigation

\section{INTRODUCTION}

The continuous descent approach (CDA) is a noisereducing procedure in which the aircraft applies an optimal rate of descent towards the final approach fix, at which point the pilot can initiate instrumental approach. CDA involves calculating flight altitude as a function of distance from the runway, and this so-called vertical navigation minimizes or even eliminates the need for engine power corrections and allows the engine to work at minimum power from the beginning of the procedure. The result is continuous descent without horizontal flight segments. This procedure has been reported to reduce fuel consumption from cruising altitude (top of descent) to final approach $305 \mathrm{~m}(1000 \mathrm{ft})$ above ground. Since this flight segment can be as long as $56 \mathrm{~km}(30 \mathrm{NM})$ and last up to 20 minutes, vertical navigation can lead to significant fuel savings.

The environmental impact of air traffic, including noise and toxic emissions, has become a key factor limiting the expansion of many airports. The rapid growth of communities around airports and increasing awareness of the environmental pollution generated by airports conflict with annual growth in air traffic. The environmental impact of airport operations leads individuals and associations in the local community to file objections with local authorities or lawsuits in court. This negative publicity then makes it difficult to introduce new runways, exacerbating the already increasing congestion around major airports. This congestion leads, in turn, to higher fuel consumption and toxic emissions.

To reduce the environmental impact of air traffic on communities located near airports and to offset relatively high fuel prices, many airports have issued specially designed CDA procedures. At the same time, an increasing number of airlines have adopted these procedures for all types of aircraft in their fleets. Despite its growing global acceptance, CDA has not officially been introduced into aircraft operations in Croatian airspace. Therefore, the present work was undertaken to verify that CDA can be implemented in this region and that it can have positive commercial and environmental benefits for airlines and airports. We measured fuel consumption of Croatia Airlines Dash-8 Q400 aircraft during routine commercial flights, from the top of the descent to landing at the airport in Split, Croatia. Approaches were performed using either the "step-down" procedure or the CDA procedure at different flight speeds under various atmospheric conditions. We hypothesized that because CDA minimizes engine power corrections during descent, it would lead to lower fuel consumption than the standard step-down approach, regardless of wind effects or air traffic control restrictions.

Our results confirmed our hypothesis that CDA can be deployed in Croatian airspace, though it places significant demands on air traffic controllers, suggesting that implementation will require adaptation by staff and systems. Our results also confirmed our hypothesis that CDA leads to fuel savings: although the financial benefits are negligible for a single flight or approach, they are significant when considered on an annual basis for a larger number of aircrafts. In addition to these financial benefits, CDA implementation can substantially reduce $\mathrm{CO}_{2}$ emissions, benefiting the environment and communities located near the airport.

The conducted research can serve airline companies to implement appropriate navigation and approach procedures that will have a positive impact on fuel economy, and therefore on the environment as well. With the reduction of the noise footprint of an aircraft during the approach, quality of life in the vicinity of the airport can be raised to a higher level.

\section{BACKGROUND AND LITERATURE REVIEW}

CDA procedures assist the aircraft crew in determining and implementing the optimal descent profile that minimizes fuel consumption, noise and toxic emissions. This involves calculations and operations that are collectively known as vertical navigation. In the CDA process, the aircraft remains at the highest possible cruise altitude for as long as possible and then descends according to an optimized profile that minimizes path corrections. 
Maximizing the length of the path for which the aircraft operates at the minimal ("idle") power setting can significantly reduce fuel consumption. Ideally, descent should start at a flight position (top of descent) determined by the flight management system, at which point the CDA procedure should also begin. Such maximization of idle power settings reduces not only fuel consumption but also noise. Aircraft noise comprises noise generated by the parts of the airplane as well as by the engine, so in CDA, with the engine at minimal noise, most of the remaining noise comes from the flaps, spoilers and landing gear [1]. The noise reduction achieved with $\mathrm{CDA}$ can be up to $5 \mathrm{~dB}$ compared to a conventional step-down approach [2], depending on the type of aircraft. The human ear clearly perceives differences of $5 \mathrm{~dB}$, and in fact a drop of only 3 $\mathrm{dB}$ implies a halving of acoustic energy, since the decibel scale is logarithmic. Since aircraft and engine noise is perceptible primarily $15-50 \mathrm{~km}$ from the point of landing, CDA is well suited for reducing aircraft noise for communities located near airports. After the aircraft crosses the final approach fix, however, CDA and conventional step-down approach procedures produce similar noise [2]. Field measurements at Louisville International Airport in the US [4] suggest that CDA can reduce $60-\mathrm{dB}$ noise contours relative to the step-down approach by $12 \%$ for a Boeing 757-200 equipped with Pratt \& Whitney engines, 33\% for a Boeing 757-200 equipped with Rolls-Royce engines and 17\% for a Boeing 767-300.

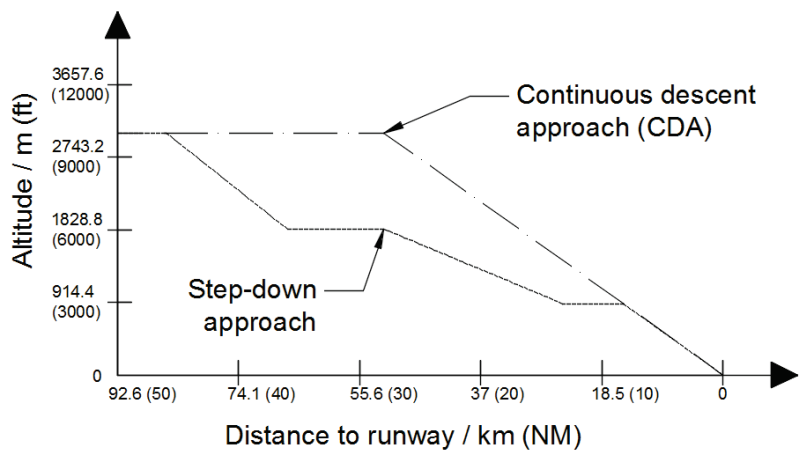

Figure 1 Comparison of descent and landing based on CDA or a conventional step-down procedure

By reducing fuel consumption, $\mathrm{CDA}$ has the additional benefit of reducing $\mathrm{CO}_{2}$ emissions; aircraft emissions of this greenhouse gas are estimated to account for $2 \%$ of all man-made $\mathrm{CO}_{2}$ emissions and $13 \%$ of all $\mathrm{CO}_{2}$ emissions from transportation sources [3]. Reducing aircraft emissions of $\mathrm{CO}_{2}$ and other toxic greenhouse gases has taken on financial significance with the introduction of emissions trading systems [3]. It also has environmental significance: complaints about respiratory difficulties in areas near airports primarily reflect high concentrations of $\mathrm{CO}_{2}, \mathrm{CO}, \mathrm{NO}_{\mathrm{x}}$ and hydrocarbons. $\mathrm{NO}_{\mathrm{x}}$ also contributes the most to global warming [1]. Airports typically monitor gas emissions above and below the boundary layer at $914 \mathrm{~m}$ (3000 ft) above the airport. Since both step-down and CDA procedures lead to only negligible differences in gas emissions above the boundary layer, research tends to focus on differences below the boundary layer, which can affect communities near the airport.

Key to the fuel efficiency of CDA is the fact that the aircraft is maintained as long as possible at cruise altitude, which prolongs the time during which ground speed can be maintained during the cruise phase of flight and thereby substantially reduces approach time. Field studies at Louisville International Airport reported average approach durations of $1808 \mathrm{sec}$ with CDA and $1926 \mathrm{sec}$ with the step-down procedure for a Boeing 757-200 [4], corresponding to a difference of $118 \mathrm{sec}$. Another field study measured an even larger difference of $147 \mathrm{sec}$ for a Boeing 767-300 (1797 vs. 1944 sec) [4]. Simulation studies using the Future ATM Concepts Evaluation Tool (FACET) and a data set of 697 flights landing at Newark Liberty International Airport in the US suggest that CDA can shave an average of 2.42 minutes off each flight [5]. At the same time, the CDA procedure saves fuel: the FACET simulations suggest an average of $57 \mathrm{~kg}$ of fuel saved per flight. These simulations further suggest that CDA is more fuel- and time-efficient for nearly every type of civilian aircraft tested, though the amount of fuel savings depends on the type of aircraft. For this reason, the authors of the FACET study recommend that when prioritizing flights for descent and landing, air traffic controllers give priority to aircraft that will save more fuel during CDA, thereby maximizing overall efficiency of airport operations. To evaluate analytical relationship between speed, altitude and fuel burn a group of researchers in their study [6] simulated CDA approach using base of aircraft data total-energy model. Results showed that CDA procedure, if applied at low speed range, could consume more fuel than conventional approach. With that in mind authors propose CDA design guidelines based on observations attained during study. Another study [7] used FACET simulations to confirm that even in highly congested airspace where delays can obstruct complete execution of CDA, implementation of CDA procedure lead to a reduction of 23-43 kg of fuel per flight. Latest studies of CDA procedures [8,9] evaluate different aspect of CDA in terms of predictability, variability and operational feasibility and trade-off between trajectory predictability and potential fuel savings. Studies by EUROCONTROL suggest that implementing CDA at a minimum of $20 \%$ of European airports would save airlines 120000 tons of fuel annually [10], which corresponds to approximately 100 million EUR and 400000 tons of $\mathrm{CO}_{2}$.

While awareness of the financial and environmental benefits of CDA has boosted its worldwide acceptance by airlines and airports alike, the procedure is not widely applied in all member states of the ICAO. This reflects primarily the need to implement simultaneously enablers and operational procedures that ensure effective use of CDA [11]. Implementation of CDA also requires safety evaluations that aim to predict all possible scenarios that can threaten flight safety and to recommend appropriate response procedures. Thus, CDA implementation requires significant commitment from stakeholders and a suitably favourable cost-benefit analysis. Even though Croatia announced in 2008 its intention to implement CDA [12], we are unaware that such analysis has been attempted.

Therefore, the present study analyses all relevant factors to show that CDA can be implemented in Croatia as a standard operating procedure for daily air traffic, suggesting that this approach procedure can be applied more widely across the Balkans and globally. Since our data were obtained using commercial aircraft in routine 
operation for the national airline, we believe our findings provide a strong basis for implementing vertical navigation in Croatia.

\section{METHODS}

The goal of this work was to compare average fuel consumption and approach duration for Croatia Airlines Dash-8 Q400 aircraft operated at different flight speeds and under various atmospheric conditions over a 6-month period at Split Airport (IATA, SPU; ICAO, LDSP). Three approach procedures were compared:

- CDA at a speed of $426 \mathrm{~km} / \mathrm{h}$ (230 knots)

- high-speed CDA

- $\quad$ standard step-down approach at $426 \mathrm{~km} / \mathrm{h}$ (230 knots).

Measurements of fuel consumption and approach durations were measured between flight levels (FL) 200 and 100 and between FL 200 and landing, reflecting the fact that cruising altitudes varied between FL 200 and 250. The approach angle was $3^{\circ}$ in all three procedures, and deceleration to configure the aircraft for landing began 22 km (12 NM) away from the runway threshold. Flaps were first adjusted by $5^{\circ}$ at a distance of $18.5 \mathrm{~km}(10 \mathrm{NM})$, while the final landing configuration occurred at $11 \mathrm{~km}(6 \mathrm{NM})$ from the runway threshold. The position of the flaps was $15^{\circ}$ for all measurements taken during final approach and landing.

Measurements were carried out over a 6-month period under various conditions of temperature, pressure, aircraft mass, wind direction and wind speed. Volumes of fuel consumed were converted into estimates of greenhouse gas emissions using the conversion that $1 \mathrm{~kg}$ of fuel spent during flight equals $3.149 \mathrm{~kg} \mathrm{CO}$ released into the atmosphere [13]. Results were analyzed statistically, and the following descriptive statistics were reported: arithmetic mean $(\mathrm{X})$, standard deviation $(\sigma)$ and coefficient of variation $(\mathrm{CV})$.

\subsection{CDA at a Speed of $426 \mathrm{~km} / \mathrm{h}$ (230 knots)}

In this procedure, the approach began at the top of descent as calculated by the vertical navigation system, and speed was maintained at $426 \mathrm{~km} / \mathrm{h}$ (230 knots) until the moment of deceleration to configure the aircraft for landing (Fig. 2 approach (2)).

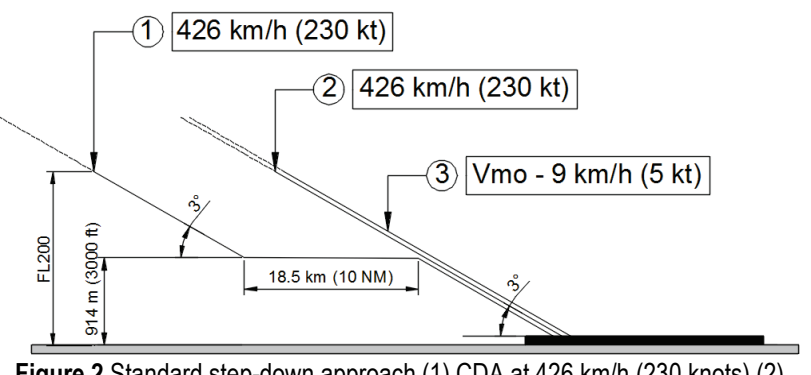

Figure 2 Standard step-down approach (1) CDA at 426 km/h (230 knots) (2), High-speed CDA (3)

The average wind component at the top of descent was $9.44 \mathrm{~km} / \mathrm{h}$ (5.1 knots) of headwind, and variation with respect to the outer air temperature was $12.3{ }^{\circ} \mathrm{C}$ (ISA DVN).

\subsection{High-speed CDA}

In this procedure, flight speed was maintained at 9 $\mathrm{km} / \mathrm{h}$ (5 knots) below the maximum operating speed (VMO) until the moment of deceleration to configure the aircraft for landing (Fig. 2 approach (3)). The maximum speed of the Dash-8 Q400 aircraft depended on altitude (Tab. 1).

Table 1 Maximal operating speeds for the Dash-8 Q400 aircraft as a function of altitude [14]

\begin{tabular}{|c|c|}
\hline Altitude $/ \mathrm{m}(\mathrm{ft})$ & $V_{\mathrm{MO}} / \mathrm{km} / \mathrm{h}(\mathrm{KIAS})$ \\
\hline $0-2438(8000)$ & $454(245)$ \\
\hline $3048(10000)$ & $522(282)$ \\
\hline $5486(18000)$ & $530(286)$ \\
\hline $6096(20000)$ & $509(275)$ \\
\hline $7620(25000)$ & $459(248)$ \\
\hline
\end{tabular}

\subsection{Standard Step-down Approach at 426 km/h (230 knots)}

In this procedure, both the descent from cruising altitude and the final approach were controlled by an instrument landing system but with a horizontal segment of

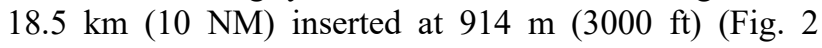
approach (1)).

\section{RESULTS \\ 4.1 CDA at a Speed of $426 \mathrm{~km} / \mathrm{h}$ (230 knots)}

Average fuel consumption $(\mathrm{kg})$, distance travelled and duration were measured for 15 flights between FL 200 and FL 100 and between FL 200 and ground during CDA at $426 \mathrm{~km} / \mathrm{h}$ (230 knots) (Tab. 2).

Table 2 Distance travelled, duration and fuel consumed during CDA at $426 \mathrm{~km} / \mathrm{h}$ (230 knots)

\begin{tabular}{|c|c|c|c|c|c|c|}
\hline \multirow{2}{*}{$\begin{array}{c}\text { 㐘 } \\
\text { 竎 }\end{array}$} & \multicolumn{2}{|c|}{ From FL 200 to FL 100} & \multicolumn{2}{c|}{ From FL 200 to ground } \\
\cline { 2 - 7 } & $\begin{array}{c}\text { Distance } \\
\text { (NM) }\end{array}$ & $\begin{array}{c}\text { Time } \\
/ \mathrm{mm}: \mathrm{ss}\end{array}$ & $\begin{array}{c}\text { Fuel } \\
\text { used } \\
/ \mathrm{kg}\end{array}$ & $\begin{array}{c}\text { Distance } \\
/ \mathrm{km}(\mathrm{NM})\end{array}$ & $\begin{array}{c}\text { Time } \\
/ \mathrm{mm}: \mathrm{ss}\end{array}$ & $\begin{array}{c}\text { Fuel } \\
\text { used } \\
/ \mathrm{kg}\end{array}$ \\
\hline 1 & $55.6(30.0)$ & $06: 52$ & 72 & $55.6(30.0)$ & $16: 58$ & 168 \\
\hline 2 & $56.1(30.3)$ & $06: 05$ & 52 & $56.1(30.3)$ & $14: 57$ & 131 \\
\hline 3 & $56.1(30.3)$ & $06: 25$ & 55 & $56.1(30.3)$ & $16: 11$ & 153 \\
\hline 4 & $55.7(30.1)$ & $06: 22$ & 57 & $55.7(30.1)$ & $15: 52$ & 152 \\
\hline 5 & $56.7(30.6)$ & $06: 04$ & 49 & $56.7(30.6)$ & $15: 18$ & 133 \\
\hline 6 & $57.2(30.9)$ & $05: 55$ & 50 & $57.2(30.9)$ & $14: 27$ & 130 \\
\hline 7 & $59.3(32.0)$ & $07: 16$ & 77 & $59.3(32.0)$ & $16: 38$ & 158 \\
\hline 8 & $56.7(30.6)$ & $06: 24$ & 54 & $56.7(30.6)$ & $15: 09$ & 135 \\
\hline 9 & $55.7(30.1)$ & $06: 23$ & 53 & $55.7(30.1)$ & $16: 23$ & 155 \\
\hline 10 & $57.6(31.1)$ & $06: 43$ & 62 & $57.6(31.1)$ & $15: 32$ & 145 \\
\hline 11 & $58.0(31.3)$ & $05: 51$ & 46 & $58.0(31.3)$ & $14: 06$ & 125 \\
\hline 12 & $58.0(31.3)$ & $06: 39$ & 57 & $58.0(31.3)$ & $15: 33$ & 141 \\
\hline 13 & $57.4(31.0)$ & $06: 35$ & 58 & $57.4(31.0)$ & $16: 09$ & 150 \\
\hline 14 & $58.2(31.4)$ & $06: 44$ & 59 & $58.2(31.4)$ & $15: 56$ & 151 \\
\hline 15 & $58.3(31.5)$ & $06: 18$ & 53 & $58.3(31.5)$ & $15: 17$ & 141 \\
\hline$X$ & $57.0(30.8)$ & $06: 26$ & 56.9 & $57.0(30.8)$ & $15: 38$ & 144.5 \\
\hline$\sigma$ & 0.58 & $00: 22$ & 8.00 & 0,33 & $00: 46$ & 11.74 \\
\hline$C V$ & $1.89 \%$ & $5.69 \%$ & $14.0 \%$ & $0.5 \%$ & $4.9 \%$ & $8.1 \%$ \\
\hline & & & & & & \\
\hline
\end{tabular}

\subsection{High-speed CDA}

The same three parameters were measured for 17 flights from FL 200 to FL 100 and from FL 200 to landing for high-speed CDA (Tab. 3). The average wind component at the top of descent was $7 \mathrm{~km} / \mathrm{h}$ (3.8 knots) of headwind, and variation with respect to the outer air temperature was $13.7^{\circ} \mathrm{C}$ (ISA DVN). 
Table 3 Distance travelled, duration and fuel consumed during high-speed CDA

\begin{tabular}{|c|c|c|c|c|c|c|}
\hline \multirow{2}{*}{$\begin{array}{c}\overrightarrow{7} \\
\overrightarrow{5}\end{array}$} & \multicolumn{2}{|c|}{ From FL 200 to FL 100} & \multicolumn{3}{|c|}{ From FL 200 to ground } \\
\cline { 2 - 7 } & $\begin{array}{c}\text { Distance } \\
/ \mathrm{km}(\mathrm{NM})\end{array}$ & $\begin{array}{c}\text { Time } \\
/ \mathrm{mm}: \mathrm{ss}\end{array}$ & $\begin{array}{c}\text { Fuel } \\
\text { used } \\
/ \mathrm{kg}\end{array}$ & $\begin{array}{c}\text { Distance } \\
/ \mathrm{km}(\mathrm{NM})\end{array}$ & $\begin{array}{c}\text { Time } \\
/ \mathrm{mm}: \mathrm{ss}\end{array}$ & $\begin{array}{c}\text { Fuel } \\
\text { used } \\
/ \mathrm{kg}\end{array}$ \\
\hline 1 & $58.2(31.4)$ & $05: 17$ & 64 & $113.9(61.5)$ & $13: 40$ & 143 \\
\hline 2 & $58.3(31.5)$ & $04: 54$ & 69 & $115.8(62.5)$ & $13: 09$ & 144 \\
\hline 3 & $57.6(31.1)$ & $05: 45$ & 72 & $113.9(61.5)$ & $14: 32$ & 142 \\
\hline 4 & $59.6(32.2)$ & $05: 36$ & 65 & $114.8(62.0)$ & $14: 13$ & 144 \\
\hline 5 & $57.2(30.9)$ & $05: 10$ & 54 & $113.3(61.2)$ & $13: 29$ & 132 \\
\hline 6 & $58.2(31.4)$ & $05: 02$ & 52 & $113.7(61.4)$ & $13: 55$ & 135 \\
\hline 7 & $58.0(31.3)$ & $06: 04$ & 75 & $113.2(61.1)$ & $15: 35$ & 175 \\
\hline 8 & $57.4(31.0)$ & $06: 12$ & 71 & $112.8(60.9)$ & $14: 35$ & 153 \\
\hline 9 & $57.4(31.0)$ & $05: 58$ & 74 & $114.3(61.7)$ & $15: 16$ & 168 \\
\hline 10 & $56.3(30.4)$ & $05: 49$ & 63 & $112.4(60.7)$ & $14: 05$ & 144 \\
\hline 11 & $57.6(31.1)$ & $05: 39$ & 68 & $112.8(60.9)$ & $14: 08$ & 150 \\
\hline 12 & $57.8(31.2)$ & $05: 32$ & 70 & $112.8(60.9)$ & $14: 11$ & 160 \\
\hline 13 & $57.2(30.9)$ & $05: 46$ & 69 & $113.0(61.0)$ & $14: 16$ & 161 \\
\hline 14 & $55.7(30.1)$ & $04: 58$ & 54 & $113.2(61.1)$ & $13: 23$ & 132 \\
\hline 15 & $58.5(31.6)$ & $05: 36$ & 71 & $113.3(61.2)$ & $14: 24$ & 159 \\
\hline 16 & $57.8(31.2)$ & $05: 30$ & 61 & $114.1(61.6)$ & $16: 21$ & 174 \\
\hline 17 & $57.4(31.0)$ & $05: 27$ & 67 & $112.8(60.9)$ & $13: 45$ & 145 \\
\hline$X$ & $57.6(31.1)$ & $05: 33$ & 65.8 & $113.5(61.3)$ & $14: 17$ & 150.6 \\
\hline$\sigma$ & $0.83(0.45)$ & $00: 22$ & 6.83 & $0.83(0.45)$ & $00: 48$ & 13.17 \\
\hline$C V$ & $1.44 \%$ & $6.63 \%$ & $10.37 \%$ & $0.74 \%$ & $5.55 \%$ & $8.74 \%$ \\
\hline
\end{tabular}

\subsection{Standard Step-down Approach at $426 \mathrm{~km} / \mathrm{h}$ (230 knots)}

Finally, the same three parameters were measured for 12 flights from FL 200 to FL 100 and from FL 200 to landing for a step-down approach at $426 \mathrm{~km} / \mathrm{h}$ (230 knots) (Tab. 4). The average wind component at the top of descent was $2.2 \mathrm{~km} / \mathrm{h}$ (1.2 knots) of headwind, and variation with respect to the outer air temperature was $12.8{ }^{\circ} \mathrm{C}$ (ISA DVN).

The values for a step-down approach from FL 200 to FL 100 overlap with the corresponding values for CDA at $426 \mathrm{~km} / \mathrm{h}$ (230 knots) (Tab. 2). In this altitude regime, both procedures involve the same actions. In contrast, the distance travelled from FL 200 to landing is longer for the step-down approach because of the 18.5-km (10-NM) horizontal segment. As a result, the step-down approach takes longer and consumes more fuel.

Table 4 Distance travelled, duration and fuel consumed during a step-down approach at $426 \mathrm{~km} / \mathrm{h}$ (230 knots)

\begin{tabular}{|c|c|c|c|c|c|c|}
\hline \multirow[b]{2}{*}{ 苛 } & \multicolumn{3}{|c|}{ From FL 200 to FL 100} & \multicolumn{3}{|c|}{ From FL 200 to ground } \\
\hline & $\begin{array}{l}\text { Distance } \\
\text { / NM }\end{array}$ & $\begin{array}{l}\text { Time } \\
\text { /mm: ss }\end{array}$ & $\begin{array}{c}\text { Fuel } \\
\text { used } \\
/ \mathrm{kg}\end{array}$ & $\begin{array}{c}\text { Distance / } \\
\text { NM }\end{array}$ & $\begin{array}{l}\text { Time } \\
/ \mathrm{mm}: \mathrm{ss}\end{array}$ & $\begin{array}{c}\text { Fuel } \\
\text { used } \\
/ \mathrm{kg}\end{array}$ \\
\hline 1 & $59.4(32.1)$ & 06:39 & 58 & $133.5(72.1)$ & $18: 10$ & 202 \\
\hline 2 & $59.6(32.2)$ & $06: 36$ & 59 & $133.9(72.3)$ & $17: 48$ & 194 \\
\hline 3 & $57.8(31.2)$ & $07: 17$ & 66 & $132.4(71.5)$ & $18: 20$ & 207 \\
\hline 4 & $58.7(31.7)$ & $07: 23$ & 69 & $133.9(72.3)$ & $19: 03$ & 223 \\
\hline 5 & $58.3(31.5)$ & $06: 57$ & 65 & $132.0(71.3)$ & $18: 43$ & 199 \\
\hline 6 & $57.8(31.2)$ & $06: 05$ & 49 & $131.3(70.9)$ & $17: 33$ & 179 \\
\hline 7 & $58.0(31.3)$ & $06: 10$ & 49 & $133.7(72.2)$ & $18: 02$ & 184 \\
\hline 8 & $55.7(30.1)$ & $05: 54$ & 45 & $132.2(71.4)$ & $17: 22$ & 175 \\
\hline 9 & $59.3(32.0)$ & $06: 28$ & 59 & $132.4(71.5)$ & $18: 11$ & 201 \\
\hline 10 & $58.7(31.7)$ & $06: 43$ & 64 & $132.6(71.6)$ & $18: 13$ & 202 \\
\hline 11 & $58.7(31.7)$ & $06: 20$ & 52 & $133.9(72.3)$ & $18: 15$ & 191 \\
\hline 12 & $58.9(31.8)$ & 06:09 & 49 & $132.6(71.6)$ & $18: 12$ & 185 \\
\hline$X$ & $58.3(31.5)$ & $06: 33$ & 57.0 & $133.0(71.8)$ & 18:09 & 195.2 \\
\hline$\sigma$ & $1.00(0.54)$ & $00: 27$ & 7.68 & $0.83(0.45)$ & $00: 26$ & 12.82 \\
\hline $\mathrm{CV}$ & $1.70 \%$ & $6.87 \%$ & $13.48 \%$ & $0.63 \%$ & $2.41 \%$ & $6.57 \%$ \\
\hline
\end{tabular}

\subsection{Comparison of Different Approach Conditions}

For flights relying on the high-speed CDA or stepdown approach, the average deviation of the actual temperature from the standard temperature based on International Standard Atmosphere conditions at flight altitude was $12.5^{\circ} \mathrm{C}$, while it was slightly less in the case of CDA at $426 \mathrm{~km} / \mathrm{h}$ (230 knots) because two flights occurred under colder conditions in October. As a result, variability was moderate to very strong $\left(\sigma \approx 4.5^{\circ} \mathrm{C}\right)$ for this approach condition. Flights for the other two approach conditions were conducted during the summer, so variability was slight $\left(\sigma \approx 2{ }^{\circ} \mathrm{C}\right)$

The average wind component at the top of descent varied within the range $1.3-9.4 \mathrm{~km} / \mathrm{h}(0.7-5.1 \mathrm{knots})$ of headwind. Individual wind component values varied from $91 \mathrm{~km} / \mathrm{h}$ (49 knots) of tailwind to $124 \mathrm{~km} / \mathrm{h}$ (67 knots) of headwind; these strong deviations from central values explain the high variability at cruising altitudes and FL 200 $(\sigma \approx 37 \mathrm{~km} / \mathrm{h}(20 \mathrm{knots}))$ as well as at FL $100(\sigma \approx 18.5$ $\mathrm{km} / \mathrm{h}(10 \mathrm{knots}))$. The data reveal that the wind speed component increased with flight altitude.

Tab. 5 describes the weather conditions for the various test flights.

Average values for specific ground range [SR(GND)] and specific air range [SR(AIR)], both measured at the top of descent, varied over the range $0.632-0.646 \mathrm{~km} / \mathrm{kg}$ (0.341-0.349 NM/kg) per torque, corresponding to approximately 55\% variation. At FL 200, high-speed CDA was associated with average SR(GND) and SR(AIR) of approximately $0.963 \mathrm{~km} / \mathrm{kg}(0.52 \mathrm{NM} / \mathrm{kg})$ with relatively slight variability and a standard variation of measurement of $0.20 \mathrm{~km} / \mathrm{kg}(0.11 \mathrm{NM} / \mathrm{kg})$; the other two approach procedures were associated with average SR(GND) and $\mathrm{SR}(\mathrm{AIR})$ values near $1.20 \mathrm{~km} / \mathrm{kg}(0.65 \mathrm{NM} / \mathrm{kg})$ with extremely low variability and a standard variation of 0.11 $\mathrm{km} / \mathrm{kg}(0.06 \mathrm{NM} / \mathrm{kg})$. For all three approach conditions, the specific range, which averaged $0.98 \mathrm{~km} / \mathrm{kg}(0.48 \mathrm{NM} / \mathrm{kg})$ at FL 100, decreased during descent. Differences in specific range between high-speed CDA and CDA at 426 $\mathrm{km} / \mathrm{h}$ (230 knots) were smaller at FL 100 than at FL 200, as a direct result of deceleration in order to achieve 444 $\mathrm{km} / \mathrm{h}(240$ knots) at FL 80; achieving 444 (240 knots) requires only slightly more torque than maintaining 426 $\mathrm{km} / \mathrm{h}$ (230 knots).

The average torque value during approach at $426 \mathrm{~km} / \mathrm{h}$ (230 knots) was $16 \%$ of the torque during the entire approach. During high-speed CDA, average was $35.8 \%$ of the torque during the entire approach at FL 200. At FL 100, average torque was $23.6 \%$ during the entire approach. The large dispersion of measured values around the central values reflects frequent torque adjustment in order to maintain the desired speed and avoid exceeding vMO.

Average rate of fuel consumption during CDA at 426 $\mathrm{km} / \mathrm{h}(230 \mathrm{knots})$ was approximately $480 \mathrm{~kg} / \mathrm{h}$ at FL 200 , and it increased progressively during descent, reaching approximately $570 \mathrm{~kg} / \mathrm{h}$ at FL 100 . Conversely, the rate of fuel consumption during high-speed CDA decreased during descent, going from $705.3 \mathrm{~kg} / \mathrm{h}$ at FL 200 to 677.1 $\mathrm{kg} / \mathrm{h}$ at FL 100 . Our results showed CDA to be fuelefficient, even though the desired speed was $9 \mathrm{~km} / \mathrm{h}(5$ knots) less than $V_{\text {MO }}(277$ knots at FL 100; Tab. 1). This efficiency reflects the optimized start of deceleration to achieve a speed of $444 \mathrm{~km} / \mathrm{h}$ (240 knots) at an altitude of $2438 \mathrm{~m}(8000 \mathrm{ft})$. Interestingly, high-speed CDA was more fuel-efficient than conventional CDA, even though it 
consumed more fuel at lower altitudes due to greater air density.

Average target vertical speed for CDA or the stepdown approach at $426 \mathrm{~km} / \mathrm{h}$ (230 knots) was $8.488 \mathrm{~m} / \mathrm{s}$ $(1671 \mathrm{ft} / \mathrm{min})$ at FL 200 and approximately $7.239 \mathrm{~m} / \mathrm{s}$ (1425 ft/min) at FL 100. In contrast, target vertical speed was higher for high-speed CDA: $9.601 \mathrm{~m} / \mathrm{s}(1890 \mathrm{ft} / \mathrm{min})$ at FL 200 and $8.173 \mathrm{~m} / \mathrm{s}(1609 \mathrm{ft} / \mathrm{min})$ at FL 100.
The standard deviation in the distance needed for an aircraft to land from FL 200 and FL 100 was $0.83 \mathrm{~km}(0.45$ NM) in all three approach conditions. This most likely reflects measurement error, since average air pressure was equal to the standard pressure of $1013.25 \mathrm{hPa}$ with only small deviations from the central value of $4 \mathrm{hPa}$.

Table 5 Atmospheric conditions during the test flights

\begin{tabular}{|c|c|c|c|c|c|c|c|c|c|}
\hline \multirow[b]{2}{*}{ Flight } & \multicolumn{3}{|c|}{ TOD } & \multicolumn{2}{|c|}{ At FL 200} & \multicolumn{2}{|c|}{ At FL 100} & \multicolumn{2}{|c|}{ At ground } \\
\hline & FL & $\begin{array}{c}\text { ISA Dev / } \\
{ }^{\circ} \mathrm{C} \\
\end{array}$ & $\begin{array}{c}\text { Wind / } \\
\mathrm{km} / \mathrm{h}(\mathrm{kt})\end{array}$ & $\begin{array}{c}\text { ISA Dev / } \\
{ }^{\circ} \mathrm{C} \\
\end{array}$ & Wind $/ \mathrm{km} / \mathrm{h}(\mathrm{kt})$ & $\begin{array}{c}\text { ISA Dev / } \\
{ }^{\circ} \mathrm{C} \\
\end{array}$ & Wind / km/h(kt) & $\begin{array}{c}\text { Temperature / } \\
{ }^{\circ} \mathrm{C} \\
\end{array}$ & $\begin{array}{c}\text { Air pressure / } \\
\mathrm{hPa}\end{array}$ \\
\hline \multicolumn{10}{|c|}{ CDA at $426 \mathrm{~km} / \mathrm{h}(230 \mathrm{knots})$} \\
\hline 1 & 240 & 12 & $124.1(67)$ & 9 & $75.9(41)$ & 5 & $59.3(32)$ & 27 & 1017 \\
\hline 2 & 250 & 13 & $-16.7(-9)$ & 13 & $-13.0(-7)$ & 13 & $-22.2(-12)$ & 25 & 1014 \\
\hline 3 & 220 & 15 & $3.7(2)$ & 12 & $5.6(3)$ & 12 & $7.4(4)$ & 32 & 1016 \\
\hline 4 & 240 & 15 & $37.0(20)$ & 14 & $25.9(14)$ & 14 & $-14.8(-8)$ & 25 & 1015 \\
\hline 5 & 250 & 14 & $-18.5(-10)$ & 14 & $-18.5(-10)$ & 14 & $-14.8(-8)$ & 26 & 1012 \\
\hline 6 & 220 & 15 & $-40.7(-22)$ & 15 & $-31.5(-17)$ & 13 & $-38.9(-21)$ & 34 & 1011 \\
\hline 7 & 230 & 13 & $42.6(23)$ & 11 & $35.2(19)$ & 12 & $44.4(24)$ & 30 & 1012 \\
\hline 8 & 250 & 14 & $-3.7(-2)$ & 13 & $9.3(5)$ & 5 & $22.2(12)$ & 30 & 1010 \\
\hline 9 & 200 & 15 & $40.7(22)$ & 14 & $50.0(27)$ & 13 & $-13.0(-7)$ & 32 & 1012 \\
\hline 10 & 240 & 15 & $50.0(27)$ & 14 & $40.7(22)$ & 10 & $14.8(8)$ & 21 & 1012 \\
\hline 11 & 230 & 16 & $-64.8(-35)$ & 15 & $-63.0(-34)$ & 13 & $-25.9(-14)$ & 25 & 1015 \\
\hline 12 & 250 & 9 & $25.9(14)$ & 9 & $22.2(12)$ & 9 & $7.4(4)$ & 31 & 1011 \\
\hline 13 & 220 & 14 & $5.6(3)$ & 14 & $13.0(7)$ & 9 & $11.1(6)$ & 23 & 1017 \\
\hline 14 & 250 & 2 & $-14.8(-8)$ & 2 & $-7.4(-4)$ & -1 & $7.4(4)$ & 20 & 1006 \\
\hline 15 & 250 & 3 & $-27.8(-15)$ & 2 & $-27.8(-15)$ & 0 & $-24.1(-13)$ & 17 & 1020 \\
\hline \multicolumn{2}{|c|}{$X$} & 12.3 & $9.4(5.1)$ & 11.4 & $7.8(4.2)$ & 9.4 & $1.3(0.7)$ & 26.5 & 1013.3 \\
\hline \multicolumn{2}{|c|}{$\sigma$} & 4.19 & $44.41(23.98)$ & 4.11 & $34.65(18.71)$ & 4.79 & $26.24(14.17)$ & 4.79 & 3.34 \\
\hline \multicolumn{2}{|c|}{$\mathrm{CV}$} & $34 \%$ & $467 \%$ & $36 \%$ & $445 \%$ & $51 \%$ & $1932 \%$ & $18.04 \%$ & $0.33 \%$ \\
\hline \multicolumn{10}{|c|}{ High-speed CDA } \\
\hline 1 & 250 & 14 & $-33.3(-18)$ & 14 & $-27.8(-15)$ & 15 & $-9.3(-5)$ & 31 & 1010 \\
\hline 2 & 240 & 15 & $29.6(16)$ & 15 & $20.4(11)$ & 14 & $-9.3(-5)$ & 32 & 1007 \\
\hline 3 & 220 & 13 & $31.5(17)$ & 11 & $31.5(17)$ & 13 & $25.9(14)$ & 33 & 1011 \\
\hline 4 & 230 & 13 & $22.2(12)$ & 11 & $7.4(4)$ & 12 & $16.7(9)$ & 33 & 1010 \\
\hline 5 & 230 & 13 & $-90.7(-49)$ & 12 & $-81.5(-44)$ & 9 & $-31.5(-17)$ & 31 & 1016 \\
\hline 6 & 250 & 12 & $-77.8(-42)$ & 12 & $-74.1(-40)$ & 12 & $-27.8(-15)$ & 31 & 1015 \\
\hline 7 & 240 & 13 & $64.8(35)$ & 13 & $75.9(41)$ & 9 & $29.6(16)$ & 20 & 1023 \\
\hline 8 & 220 & 14 & $63.0(34)$ & 12 & $59.3(32)$ & 8 & $55.6(30)$ & 14 & 1022 \\
\hline 9 & 240 & 12 & $51.9(28)$ & 10 & $40.7(22)$ & 11 & $40.7(22)$ & 23 & 1011 \\
\hline 10 & 220 & 15 & $22.2(12)$ & 14 & $13.0(7)$ & 15 & $13.0(7)$ & 28 & 1009 \\
\hline 11 & 240 & 13 & $51.9(28)$ & 12 & $31.5(17)$ & 11 & $-5.6(-3)$ & 20 & 1018 \\
\hline 12 & 230 & 14 & $9.3(5)$ & 13 & $7.4(4)$ & 13 & $5.6(3)$ & 27 & 1015 \\
\hline 13 & 220 & 14 & $-1.9(-1)$ & 14 & $3.7(2)$ & 13 & $3.7(2)$ & 32 & 1014 \\
\hline 14 & 250 & 14 & $-42.6(-23)$ & 14 & $-25.9(-14)$ & 13 & $-5.6(-3)$ & 27 & 1013 \\
\hline 15 & 240 & 13 & $18.5(10)$ & 13 & $18.5(10)$ & 14 & $5.6(3)$ & 30 & 1019 \\
\hline 16 & 220 & 15 & $-22.2(-12)$ & 14 & $-18.5(-10)$ & 14 & $7.4(4)$ & 27 & 1016 \\
\hline 17 & 220 & 16 & $24.08(13)$ & 15 & $24.08(13)$ & 15 & $-1.85(-1)$ & 28 & 1014 \\
\hline \multicolumn{2}{|c|}{$X$} & 13.7 & $7.04(3.80)$ & 12.9 & $6.30(3.40)$ & 12.4 & $6.67(3.60)$ & 27.5 & 1014.3 \\
\hline \multicolumn{2}{|c|}{$\sigma$} & 1.07 & $44.89(24.24)$ & 1.41 & $40.45(21.84)$ & 2.12 & $21.85(11.80)$ & 5.20 & 4.34 \\
\hline \multicolumn{2}{|c|}{$\mathrm{CV}$} & $8 \%$ & $634 \%$ & $11 \%$ & $651 \%$ & $17 \%$ & $329 \%$ & $18.94 \%$ & $0.43 \%$ \\
\hline \multicolumn{10}{|c|}{ Step-down approach at $426 \mathrm{~km} / \mathrm{h}$ (230 knots) } \\
\hline 1 & 250 & 8 & $29.6(16)$ & 14 & $40.7(22)$ & 14 & $20.4(11)$ & 17 & 1013 \\
\hline 2 & 250 & 14 & $20.4(11)$ & 13 & $22.2(12)$ & 13 & $-3.7(-2)$ & 32 & 1015 \\
\hline 3 & 220 & 14 & $63.0(34)$ & 13 & $53.7(29)$ & 14 & $38.9(21)$ & 32 & 1010 \\
\hline 4 & 250 & 12 & $44.4(24)$ & 11 & $63.0(34)$ & 12 & $59.3(32)$ & 30 & 1012 \\
\hline 5 & 240 & 16 & $51.9(28)$ & 15 & $42.6(23)$ & 14 & $25.9(14)$ & 21 & 1013 \\
\hline 6 & 250 & 14 & $-48.2(-26)$ & 13 & $-38.9(-21)$ & 15 & $-9.3(-5)$ & 37 & 1014 \\
\hline 7 & 230 & 10 & $-50.0(-27)$ & 10 & $-38.9(-21)$ & 6 & $-16.7(-9)$ & 30 & 1013 \\
\hline 8 & 250 & 9 & $-77.8(-42)$ & 9 & $-66.7(-36)$ & 8 & $-37.0(-20)$ & 27 & 1014 \\
\hline 9 & 240 & 14 & $-1.9(-1)$ & 13 & $3.7(2)$ & 16 & $-5.6(-3)$ & 27 & 1018 \\
\hline 10 & 220 & 16 & $18.5(10)$ & 14 & $18.5(10)$ & 15 & $11.1(6)$ & 36 & 1015 \\
\hline 11 & 250 & 15 & $-14.8(-8)$ & 14 & $-22.2(-12)$ & 15 & $-3.7(-2)$ & 30 & 1015 \\
\hline 12 & 250 & 11 & $-9.3(-5)$ & 11 & $-18.5(-10)$ & 11 & $-18.5(-10)$ & 22 & 1014 \\
\hline \multicolumn{2}{|c|}{$X$} & 12.8 & $2.22(1.20)$ & 12.5 & $5.00(2.70)$ & 12.8 & $5.19(2.80)$ & 28.4 & 1013.8 \\
\hline & & 2.59 & $42.23(22.80)$ & 1.76 & $39.98(21.59)$ & 2.92 & $25.91(13.99)$ & 5.74 & 1.86 \\
\hline & & $20 \%$ & $1954 \%$ & $14 \%$ & $810 \%$ & $23 \%$ & $509 \%$ & $20.19 \%$ & $0.18 \%$ \\
\hline
\end{tabular}

As we expected, high-speed CDA gave the fastest approach of 14:17 minutes from FL 200 to landing and
5:33 minutes from FL 200 to FL 100 . The corresponding times for CDA at $426 \mathrm{~km} / \mathrm{h}$ (230 knots) were slightly 
longer at 15:38 and 6:26 minutes. Even longer were the corresponding times for the standard step-down approach at $426 \mathrm{~km} / \mathrm{h}$ (230 knots), 16:19 and 6:33 minutes (Fig. 3). Even though the first two CDA procedures occurred at 426 $\mathrm{km} / \mathrm{h}$ (230 knots), the standard step-down procedure was still 40 seconds longer. This is because the speed during the horizontal segment at $914 \mathrm{~m}(3000 \mathrm{ft})$ was lower than the speed during the corrective segment at FL 200. The duration of approach was similar from FL 200 to FL 100 for all three conditions, reflecting the fact that they involved the same operating technique. The results show that the approach time from FL 100 to landing was longer than the approach from FL 200 to FL 100, reflecting the slower flight speed at lower altitudes and the deceleration regime to achieve a final approach speed for landing.

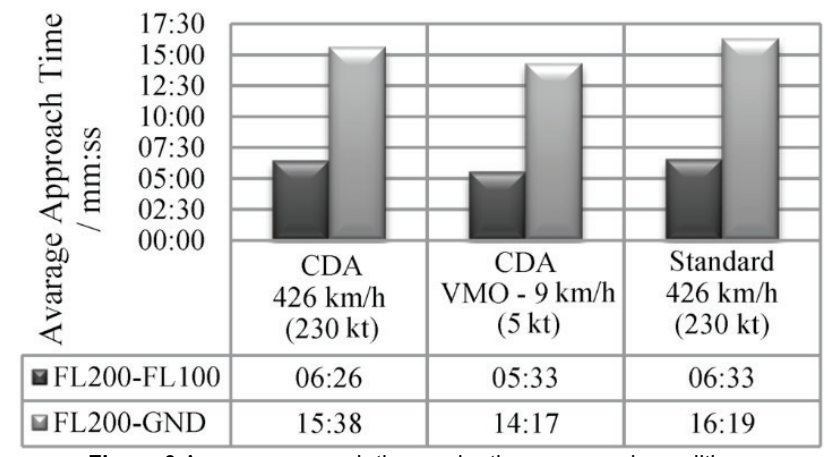

Figure 3 Average approach time under three approach conditions

The smallest fuel consumption during descent from FL 200 to FL 100 was $57 \mathrm{~kg}$, measured during CDA and the step-down approach at $426 \mathrm{~km} / \mathrm{h}$ (230 knots) (Fig. 4). The greatest fuel consumption between FL 200 and FL 100 $(65.8 \mathrm{~kg})$ was observed during high-speed CDA. Between FL 200 and landing, CDA at $426 \mathrm{~km} / \mathrm{h}$ (230 knots) gave the smallest average fuel consumption (144.5 $\mathrm{kg}$ ), compared to $150.6 \mathrm{~kg}$ for high-speed CDA. The greatest consumption between FL 200 and landing was $164.2 \mathrm{~kg}$ during the step-down approach. In all three-approach conditions, much more fuel was consumed when descending from FL 100 to landing, than when descending from FL 200 to FL 100.

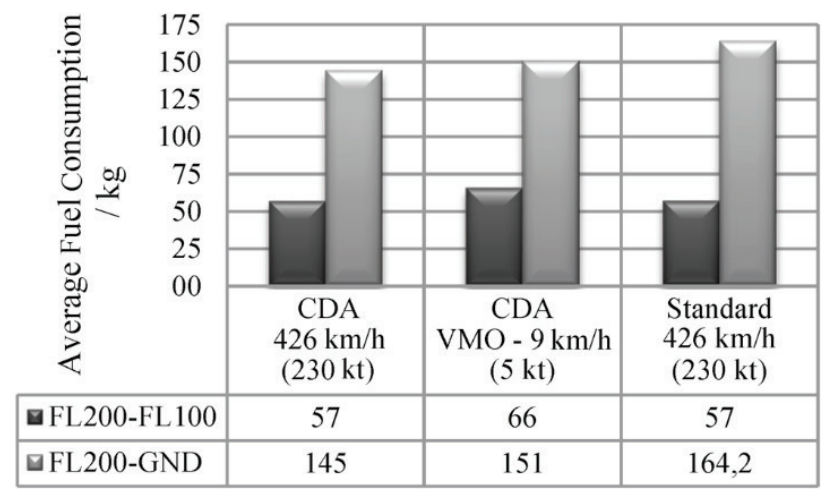

Figure 4 Average fuel consumption for three approach conditions

Comparison of the two CDA procedures shows that high-speed CDA lasted 1:20 minutes less (8,6\% reduction), while CDA at $426 \mathrm{~km} / \mathrm{h} \quad(230$ knots $)$ consumed approximately $6 \mathrm{~kg}$ less fuel (4\% reduction). Comparison of CDA at $426 \mathrm{~km} / \mathrm{h}$ (230 knots) with the standard stepdown approach shows that CDA was an average of 40 seconds shorter $(4.2 \%)$ and consumed an average of $20 \mathrm{~kg}$ less fuel $(12 \%)$. Taking into account the ratio of fuel consumed between FL 200 and landing to fuel consumed during the entire approach and landing (Tab. 6), we conclude that CDA can cut the total amount of fuel required for one flight by up to $3 \%$. These results apply only to aircraft with turbo-prop engines.

Table 6 Fuel consumed during descent from FL 200 to landing as a percentage of fuel consumed during the entire flight

\begin{tabular}{|c|c|c|c|c|c|c|c|c|c|}
\hline \multirow[b]{2}{*}{ Flight } & \multicolumn{3}{|c|}{ High-speed CDA } & \multicolumn{3}{|c|}{ CDA at $426 \mathrm{~km} / \mathrm{h}$ (230 knots) } & \multicolumn{3}{|c|}{ Step-down approach } \\
\hline & $\begin{array}{c}\text { Consumed } \\
\text { during descent } \\
/ \mathrm{kg}\end{array}$ & $\begin{array}{l}\text { Consumed } \\
\text { during entire } \\
\text { flight / kg }\end{array}$ & $\%$ & $\begin{array}{l}\text { Consumed } \\
\text { during descent } \\
/ \mathrm{kg}\end{array}$ & $\begin{array}{l}\text { Consumed } \\
\text { during entire } \\
\text { flight / kg }\end{array}$ & $\%$ & $\begin{array}{l}\text { Consumed } \\
\text { during descent } \\
/ \mathrm{kg}\end{array}$ & $\begin{array}{l}\text { Consumed } \\
\text { during entire } \\
\text { flight / kg }\end{array}$ & $\%$ \\
\hline 1 & 143 & 1094 & 13.1 & 168 & 1303 & 12.9 & 202 & 1525 & 13.3 \\
\hline 2 & 144 & 891 & 16.2 & 131 & 1739 & 7.5 & 194 & 1487 & 13.1 \\
\hline 3 & 142 & 676 & 21.1 & 153 & 710 & 21.6 & 207 & 727 & 28.5 \\
\hline 4 & 144 & 1258 & 11.5 & 152 & 641 & 23.7 & 223 & 1582 & 14.1 \\
\hline 5 & 132 & 1037 & 12.7 & 133 & 1412 & 9.4 & 199 & 696 & 28.6 \\
\hline 6 & 135 & 1115 & 12.1 & 130 & 589 & 22.1 & 179 & 953 & 18.8 \\
\hline 7 & 175 & 643 & 27.2 & 158 & 751 & 21.1 & 184 & 1554 & 11.8 \\
\hline 8 & 153 & 720 & 21.2 & 135 & 1227 & 11.0 & 175 & 1143 & 15.3 \\
\hline 9 & 168 & 666 & 25.2 & 155 & 1567 & 9.9 & 201 & 2242 & 8.9 \\
\hline 10 & 144 & 650 & 22.1 & 145 & 1205 & 12.0 & 202 & 630 & 32.1 \\
\hline 11 & 150 & 1235 & 12.1 & 125 & 888 & 14.1 & 191 & 1175 & 16.3 \\
\hline 12 & 160 & 661 & 24.2 & 141 & 1211 & 11.6 & 185 & 1361 & 13.6 \\
\hline 13 & 161 & 656 & 24.5 & 150 & 672 & 22.3 & - & - & - \\
\hline 14 & 132 & 1222 & 10.8 & 151 & 1214 & 12.4 & - & - & - \\
\hline 15 & 159 & 635 & 25.1 & 141 & 1102 & 12.8 & - & - & - \\
\hline 16 & 174 & 683 & 25.5 & - & - & - & - & - & - \\
\hline 17 & 145 & 621 & 23.4 & - & - & - & - & - & - \\
\hline$X$ & 150.7 & 850.8 & 19.3 & 144.5 & 1082.1 & 14.9 & 195.2 & 1256.3 & 17.9 \\
\hline$\sigma$ & 13.17 & 240.5 & 5.8 & 11.7 & 345.1 & 5.3 & 12.8 & 447.3 & 7.3 \\
\hline$C V$ & $8.7 \%$ & $28.3 \%$ & $30.3 \%$ & $8.1 \%$ & $31.9 \%$ & $35.6 \%$ & $6.6 \%$ & $35.6 \%$ & $40.6 \%$ \\
\hline
\end{tabular}

Average fuel savings of $20 \mathrm{~kg}$ per flight relative to the conventional step-down approach correspond to a reduction in $\mathrm{CO}_{2}$ emissions of approximately $63 \mathrm{~kg}$. This reduction, if we assume 15000 Dash Q400-type flights in
Croatian airspace each year, would translate to a total annual reduction of 944.7 tons.

Our results establish that CDA can provide fuel, time and emissions benefits over the conventional step-down 
approach for smaller commercial aircraft in Croatia. Future research should directly measure noise levels and toxic gas emissions for the different types of approach conditions. Such studies should also consider a wider array of weather conditions. Our measurements were restricted to a few altitudes: $6096 \mathrm{~m}(20000 \mathrm{ft}), \mathrm{FL} 200(1013.25 \mathrm{hPa}), \mathrm{FL}$ 100 , and landing. Our results point to a significant effect of wind on fuel consumption: a greater head wind component prolongs approach, which consumes more fuel. We also noticed that differences in aircraft weight and variations in temperature and pressure did not significantly affect fuel consumption, though further studies are needed to quantify these effects.

Future studies should also examine the practical feasibility of implementing CDA procedures in Croatian airspace, given that it places substantial additional demands on air traffic management [8]. For example, it may not be feasible to implement CDA in terminal areas, where air traffic density is high. Further work should address this question, as well as the effects of CDA on flight safety, flight delays and other aspects of air traffic.

\section{CONCLUSION}

Although the Air Navigation Service Provider and other operators in Croatian airspace have not implemented CDA, our study suggests that doing so would bring significant financial and environmental benefits. Although CDA with vertical navigation reduces the total amount of fuel needed for one flight/approach by only $1-3 \%$, these savings become substantial when calculated over the entire number of flight operations and all aircraft in a fleet. This fuel reduction translates to a reduction in $\mathrm{CO}_{2}$ emissions.

The present study was restricted to commercial twoengine turbo-prop aircraft and it involved measurements only of approach distance, duration, and fuel consumption. It was proved that airline companies can apply CDA procedures within their normal operations even though they are still not implemented as part of standard operating procedures. Future studies should measure directly the emission of greenhouse gases during descent as well as the noise perceived by communities near the airport. Despite the limitations in our data, we were able to show that strong headwind lengthens the approach and therefore increases fuel consumption. In addition, differences in aircraft mass or in air temperature or pressure do not appear to significantly affect fuel consumption, though further work is needed to quantify these effects precisely. This work will require specialized equipment and calculation of aerodynamic coefficients. In addition to these specialized questions about CDA, studies should also examine its optimal implementation by airlines and airports and its effects on air traffic management, including safety, delays and other performance parameters.

Nevertheless, positive effect of CDA in aircraft operations during approach have beneficial outcome on airline business management in terms of fuel savings, thus having significant positive ecological impact.

\section{REFERENCES}

[1] Alam, S., Nguyen, M. H., Abbass, H. A., Lokan, C., Ellejmi, M., \& Kirby, S. (2010, October). A dynamic continuous descent approach methodology for low noise and emission. In $29^{\text {th }}$ Digital Avionics Systems Conference IEEE, pp. 1-E. https://doi.org/10.1109/DASC.2010.5655502
[2] Environmental Research and Consultancy Department. Basic Principles of the Continuous Descent Approach (CDA) for the Non-Aviation Community, Civil Aviation Authority, London. Retrieved from: http://mag-umbraco-medialive.s3.amazonaws.com/1006/ caaplusbasicplusprinciplesplusofpluscda.pdf

[3] Sarkar, A. N. (2012). Evolving green aviation transport system: a holistic approach to sustainable green market development. American journal of climate change, 1(3), 164-180. https://doi.org/10.4236/ajcc.2012.13014

[4] Clarke, J. P., Bennett, D., Elmer, K., Firth, J., Hilb, R., Ho, N, \& Sizov, N. (2006). Development, design, and flight test evaluation of a continuous descent approach procedure for nighttime operation at Louisville International Airport (No. PARTNER-COE-2005-002). Partnership for Air Transportation Noise and Emissions Reduction.

[5] Cao, Y., Sun, D., \& DeLaurentis, D. A Preliminary Study on Operational Feasibility of Continuous Descent Approach. School of Aeronautics and Astronautics, Purdue University, West Lafayette, IN, USA, 2011

[6] Jin, L., Cao, Y., \& Sun, D. (2013). Investigation of potential fuel savings due to continuous-descent approach. Journal of aircraft, 50(3), 807-816. https://doi.org/10.2514/1.C032000

[7] Cao, Y., Jin, L., Nguyen, N. V., Landry, S., Sun, D., \& Post, J. (2014). Evaluation of Fuel Benefits Depending on Continuous Descent Approach Procedures. Air Traffic Control Quarterly, 22(3), 251-275. https://doi.org/10.2514/atcq.22.3.251

[8] Pradeep, P., \& Wei, P. (2017, March). Predictability, variability and operational feasibility aspect of CDA. In 2017 IEEE Aerospace Conference (pp. 1-14). IEEE. https://doi.org/10.1109/AERO.2017.7943728

[9] Jia, Y. \& Cai, K. (2018, September). The Trade-off between Trajectory Predictability and Potential Fuel Savings for Continuous Descent Operations. In 2018 IEEE/AIAA 37th Digital Avionics Systems Conference (DASC) (pp. 1-6). IEEE. https://doi.org/10.1109/DASC.2018.8569886

[10] IATA/EUROCONTROL/CANSO (2008, August). Flight Efficiency Plan - Fuel and emissions savings.

[11] De Muynck, R. J., Verhoeff, L., Verhoeven, R. P. M., \& Gelder, N. D. (2008, September). Enabling Technology Evaluation for Efficient Continuous Descent Approaches. $26^{\text {th }}$ International Congress of the International Council of the Aeronautical Sciences, Anchorange, USA, 14-19.

[12] EUROCONTROL (2008, March). Local Convergence and Implementation Plan for Croatia.

[13] EUROCNTROL (2013, September). Standard Inputs for EUROCONTROL Cost Benefit Analyses, Edition 6.0

[14] Bombardier Inc. (2011). Aeroplane Operating Manual. Downsiew Ontario, Canada

\section{Contact information:}

Petar ANDRAŠl, mag. ing. aeronaut.

(Corresponding author)

University of Zagreb,

Faculty of Transport and Traffic Sciences

Vukelićeva 4, 10000 Zagreb, Croatia

petar.andrasi@fpz.hr

Doris NOVAK, prof. dr. sc.

University of Zagreb,

Faculty of Transport and Traffic Sciences

Vukelićeva 4, 10000 Zagreb, Croatia

doris.novak@fpz.hr

Antonio RATKOVIĆ, capt

Croatia Airlines d.d.

Bani 75b, 10010 Buzin, Croatia

antonio.ratković@croatiaairlines.hr 